\title{
Integrated Lithographic Molding for Microneedle-Based Devices
}

\author{
Regina Luttge, Erwin J. W. Berenschot, Meint J. de Boer, Dominique M. Altpeter, \\ Elwin X. Vrouwe, Albert van den Berg, and Miko Elwenspoek
}

\begin{abstract}
This paper presents a new fabrication method consisting of lithographically defining multiple layers of high aspect-ratio photoresist onto preprocessed silicon substrates and release of the polymer by the lost mold or sacrificial layer technique, coined by us as lithographic molding. The process methodology was demonstrated fabricating out-of-plane polymeric hollow microneedles. First, the fabrication of needle tips was demonstrated for polymeric microneedles with an outer diameter of $250 \mu \mathrm{m}$, through-hole capillaries of $75-\mu \mathrm{m}$ diameter and a needle shaft length of $430 \mu \mathrm{m}$ by lithographic processing of SU-8 onto simple v-grooves. Second, the technique was extended to gain more freedom in tip shape design, needle shaft length and use of filling materials. A novel combination of silicon dry and wet etching is introduced that allows highly accurate and repetitive lithographic molding of a complex shape. Both techniques consent to the lithographic integration of microfluidic back plates forming a patchtype device. These microneedle-integrated patches offer a feasible solution for medical applications that demand an easy to use Point-of-Care sample collector, for example, in blood diagnostics for lithium therapy. Although microchip capillary electrophoresis glass devices were addressed earlier, here, we show for the first time the complete diagnostic method based on microneedles made from SU-8.

[2006-0110]
\end{abstract}

Index Terms-Blood, deep reactive-ion etching (DRIE), diagnostics, lithographic molding, microneedle, multilayer lithography, Point-of-Care, preprocessed substrate, SU-8.

\section{INTRODUCTION}

$\mathbf{F}$ ABRICATION processes of hollow silicon microneedles with dedicated tip shapes have widely been broadened due to advances in sophisticated combination of wet and dry etching methods [1]-[6]. Specifically, out-of-plane microneedles received attention for the application in microstructured transdermal drug delivery patches [7], [8] but applications may also be in extraction of fluids from the body [9]-[12]. For these purposes, an integrated microneedle patch should ensure that a sufficient volume is sampled or delivered through the mi-

Manuscript received June 14, 2006; revised February 19, 2007. This work was supported in part by NanoPass, Ltd., Nazareth Illit, Israel, and in part by the Dutch Foundation of Science and Technology, The Netherlands, under STW Project 5370. Subject Editor F. Ayazi.

R. Luttge, E. J. W. Berenschot, M. J. de Boer, D. M. Altpeter, A. van den Berg, and M. Elwenspoek are with the MESA ${ }^{+}$Institute for Nanotechnology, University of Twente, 7500AE, Enschede, The Netherlands (e-mail: r.luttge@tnw.utwente.nl; j.w.berenschot@utwente.nl; m.j.deboer@ utwente.nl; d.m.altpeter@ewi.utwente.nl; m.elwenspoek@el.utwente.nl).

E. X. Vrouwe is with the $\mathrm{MESA}^{+}$Institute for Nanotechnology, University of Twente, 7500AE, Enschede, The Netherlands, and also with the Micronit Microfluidics B.V., 7521 PV Enschede, The Netherlands (e-mail: elwin.vrouwe@micronit.nl).

Color versions of one or more of the figures in this paper are available online at http://ieeexplore.iee.org.

Digital Object Identifier 10.1109/JMEMS.2007.899339 crostructured patch even when small-diameter fluidic conduits are used that are demanded for minimal invasive applications. Therefore, a multitude of microneedles arranged in an array fashion is pursued in this paper. Next to a high enough sampling capacity and skin penetration performance both of which is achieved in the proper definition of number, length, and tip shape of the integrated needles it is sought that the conduits remain open after insertion. An off-centered flow channel toward a sharp tip should assist to fulfill this requirement. To realize this type of microneedles in an out-of-plane configuration, silicon micromachining demonstrated unique capabilities. Despite that silicon microneedles have been studied by several groups in the field of drug delivery devices, the basic concept of silicon out-of-plane needles has its limitations specifically in processing costs, biocompatibility and achievement of needle length. Instead, these demands can be met by processing from a master structure, which can be repeatedly reproduced in combination with high aspect-ratio photolithography, coined lithographic molding. Here, a unique 3-D tip shape is pursued in the etched master structure while the shaft of the needle structure is formed by lithography. A preprocessed silicon substrate with a defined release coating can be used for such replication purposes. A replication process allows modifications of needle properties by the choice of materials but maintains the characteristics of the needle design within the mold structure, which is a specific advantage compared to the other microelectromechanical systems (MEMS) fabrication techniques for microneedles. In respect to biocompatibility, various MEMS materials were tested throughout the recent years, including silicon and SU-8 [13]. So far, there is not a final conclusion and Food and Drug Administration (FDA) approval will depend on application specific testing, such as, for example, given by Stangegaard et al. [14] applying genome expression profiling using deoxyribonucleic acid microarrays for determining biocompatibility of polymeric surfaces. The process described in Section IV offers for the first time a microneedle fabrication process where the needle material can be modified but still keeping the unique tip geometry for biocompatibility in vitro and in vivo tests. This paper describes two new fabrication processes that permit the manufacture of polymeric needles with a specific tip shape and a flexible needle shaft length interconnected to a back plate. Lithographic molding in combination with multilayer processing allows increasing the needle shaft length nearly at will. The first process (Section III) uses the unique high-aspect-ratio capabilities of SU-8 on simple v-grooves, while in the second process (Section IV), which is based on a specific 3-D shape of an existing (proven) silicon microneedle design [4], depressions 
are formed in a silicon substrate for replication purposes. The latter offers the advantage to transfer the unique tip shape in a variety of polymers also, including nonphotosensitive materials. Both processes deliver the capacity for batch-fabricated integration with other MEMS components using a photopolymer as demonstrated with the example of the attachment of microneedles to a microrail structure instead of a solid back plate. This paper will present these two alternative costcompetitive UV-MEMS fabrication routes. Although the techniques are of general interest in MEMS design, for example, for the integration of microoptical components with lab-ona-chip devices, here, we demonstrate microfluidic integrated microneedle arrays useful in analytic sample transfer [15], [16].

\section{High Aspect-Ratio Polymer Fabrication}

Previously, Park et al. [17], [18] introduced micromachined needle-shaped, biodegradable microstructures fabricated by the replication of an SU-8 master structure. The technology involves the fabrication of cylindrical SU-8 primary structures in a first lithographic step. Subsequently, patterned metal deposition takes place and dry etching is applied to create a beveled SU-8 tip. This master structure is transferred twice. First, a secondary mold structure is received by silicone elastomer thermosetting. Second, the secondary mold acts as a master for the replication of the needle shape into a tertianary polymeric material of choice, e.g., biodegradable polyglycolic acid. This type of microneedles, although very sophisticated and elegant in terms of their intended application in drug delivery, allows only a limited control on the definition of tip shapes. The application as a sample collector is also prohibited because of the lack of a microfluidic feature.

Another technique demonstrating needle-type SU-8 structures has been presented by Han et al. [19]. The authors describe complex 3-D patterning of SU-8 using inclined UV lithography. Although the technique is very promising (freedom of design, including the opportunity to create hollow microneedle-type features) this method cannot be performed within a standard mask aligner. Also, the inclined exposure technique has not yet been demonstrated to achieve sharp tips within very thick resist layers greater than $300 \mu \mathrm{m}$ for sufficient needle height, which is a demand for transdermal sampling applications.

A method to overcome the limitation in feature height is the use of X-ray lithography and pursue inclined exposure leading to needle-type shapes as it has been shown, for example, by Turner et al. [20] using SU-8 and Matsuzuka et al. [21], who were using polymethyl methacrylate. Again, hollow structures suitable for microfluidic conduits within a sharp tip were not yet demonstrated by these authors. Moon and Lee [22] published microneedle structures manufactured by X-ray lithography. In their work, indeed several requirements for microfluidic microneedles were addressed. However, the fact that X-ray lithography is not a widely accessible manufacturing technique restricts a fast development process of smart delivery and diagnostic products.

A few publications describe ultrathick SU- 8 features by UVlithography, which would also circumvent the limitations on the height of the microneedle and still apply a costs competitive polymer batch-fabrication within a MEMS UV-lithographic process line [23]. However, these efforts aiming either for planar microchannel features in combination with UV-glue and glass substrates or solid SU-8 pillars inlcluding microtubes and do not satisfy the need for complex MEMS and microfluidic integration of microneedle devices as intended by us. As an alternative, a multilayer process meets the demands for integrated medical patches that can be batch fabricated better because of the compatibility to established MEMS process lines.

Several authors demonstrated integrated microfluidic devices using a multilayer lithographic approach, for example, Gadre et al. [24] presented a fluid encapsulated dermal patch using multilayered SU-8 for diagnostic purpose. Earlier, Heuschkel et al. [25] demonstrated buried microchannels in photopolymer (SU-8) for a multifunctional system that demands biocompatibility to chick embryonic motoneurons. Chuang et al. further developed the technique to generate stacked microfluidic components [26]. Among other recent publications, Jackman et al. [27], who demonstrated on-line UV detection within a microfluidic system employing SU-8, confirm the importance of SU-8 processes for integrated microfluidic analytical devices [28], [29]. These examples show a strong trend toward the manufacture of devices of complex integrated functionality applying established technological routes of MEMS fabrication instead of moving to alternative routes, for example, polymer injection molding in combination with laser ablation, which was demonstrated for the fabrication of conical hollow microneedles by Trichur et al. [30]. Following the trends set in MEMS integration, the multilayer sequence introduced in this paper combines unique silicon fabrication capabilities with high aspect-ratio batch-processing techniques as known from SU-8 UV-lithography [31], [32]. Besides of making use of simple pyramidal features already known in the art of silicon micromachining [33]-[35] a completely new process for 3-D lithographic molding from a silicon substrate containing the inverted shape of a unique microneedle tip that has been recognized as suitable for skin penetration is introduced by us [4]. The use of this novel process in MEMS could also allow the replication of other complex shapes achieved by silicon machining into a broad choice of materials, including the ones being nonphotosensitive, and thus broaden the utility of the lithographic molding technique beyond the field of microneedle applications in the medical field.

\section{Fabrication of Simple Tip Shapes}

Needle-like shapes (microneedle arrays) can be formed by lithographic processing onto a patterned substrate surface. The substrate can be structured, for example, by silicon bulk micromachining techniques using anisotropic and isotropic wet etching as shown in Fig. 1 [36]-[38].

The dimensions of the grid $d$ and $w$ are technology dependent variables and define the layout of the needle array. In this paper, the lithographic definition of needle shafts was performed on silicon substrates that act as a lost mold, when the structures are released, for example, in potassium hydroxide, which is an established etchant for silicon. For silicon micromachined 


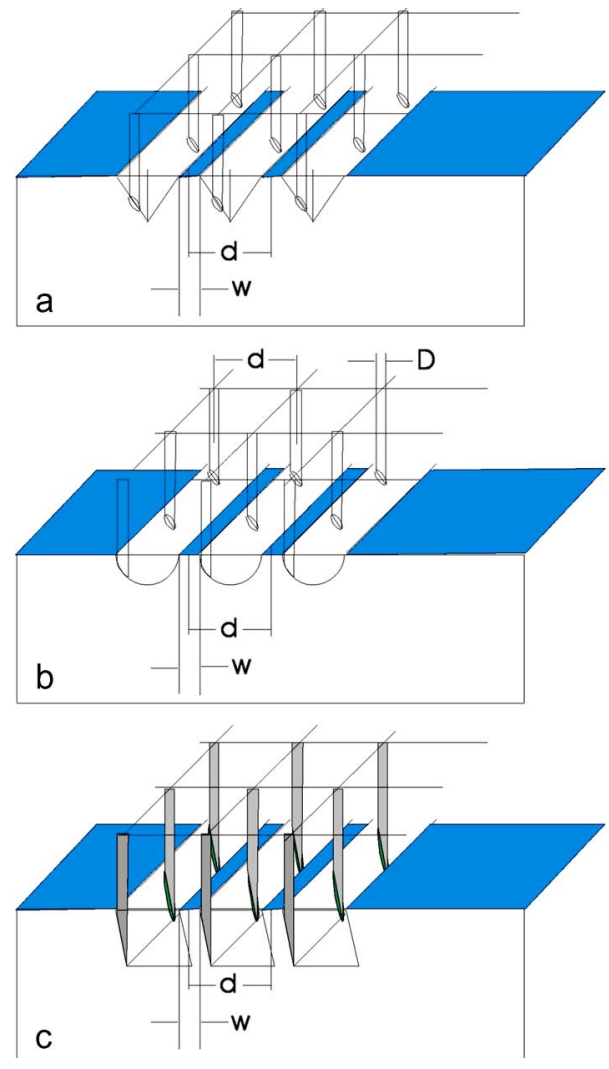

Fig. 1. Needle-like shapes on prepatterned substrate surface (a) anisotropic silicon micromachining in (100) wafer, (b) isotropic micromachining, (c) anisotropic silicon micromachining in (111) wafer.

substrates, a repetitive mold can be realized, too, by protecting the bulk silicon with a suitable masking material and additional deposition of a sacrificial layer. Various sacrificial layer techniques are known in the art [36]. In this section, we present the batch fabrication of thick photoresist microneedles using SU-8 and anisotropic silicon wet etching to form simple depressions, i.e., v-grooves. The needles are monolithic integrated with a back plate by applying multilayer lithography leading here to a maximal needle length of $430 \mu \mathrm{m}$ and a back plate thickness of $200 \mu \mathrm{m}$ as depicted in Section VI. The SU-8 photoresist process onto the silicon v-grooves is described in detail in Fig. 2. Step 1 consists in the preparation of the silicon surface. The thermally oxidized silicon wafer $\boldsymbol{a}$ is lithographically patterned (mask 1) and etched in buffered hydrofluoric acid. Subsequently, the silica $\boldsymbol{b}$ is used as a mask for potassium hydroxide $(\mathrm{KOH})$ etching of the v-grooves $c$ [36]. The substrate crystallography and the mask pattern is designed such that the (111) planes meet at a depth, which is predefined by the size of the mask openings $d$, here $550 \mu \mathrm{m}$.

In step 2, a first level of SU-8 100, a negative acting high aspect-ratio resist, is dispensed on the prepatterned silicon substrate $\boldsymbol{a}$, spin-coated to the according thickness $\boldsymbol{e}$, which leads to the desired needle height.

In step 3, the photoresist is lithographically processed at a Karl Suss maskaligner using the mask 2. We demonstrate the process with needles aligned on a constant grid size forming an equidistant array of $25(5 \times 5)$ needles with a diameter of $250 \mu \mathrm{m}$, a needle through-hole with a diameter of $75 \mu \mathrm{m}$
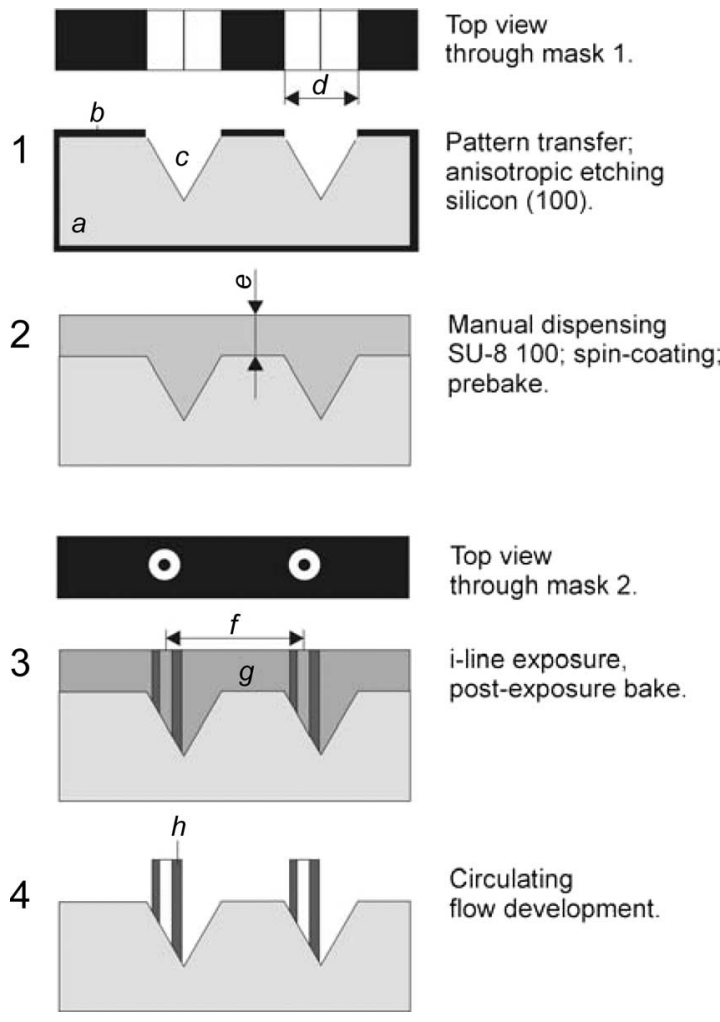

Fig. 2. Schematic process steps of polymer microneedles on preprocessed v-grooves.

TABLE I

Data SheET For a Two LeVEL SU-8 100 Process LeAdiNG TO AN INTEGRATED NEEDLE SHAFT LENGTH OF $430 \mu \mathrm{m}$ AND A BACK-Plate THICKNESS OF $200 \mu \mathrm{m}$

\begin{tabular}{|c|c|c|c|}
\hline \multicolumn{2}{|l|}{ Process step* } & $\begin{array}{l}1^{\text {st }} \text { level: } \\
\text { needles }\end{array}$ & $\begin{array}{l}2^{\text {nd }} \text { level: } \\
\text { back plate }\end{array}$ \\
\hline \multicolumn{2}{|l|}{ Dehydration } & $120^{\circ} \mathrm{C}, 5 \mathrm{~min}$ & $120^{\circ} \mathrm{C}, 5 \mathrm{~min}$ \\
\hline \multirow[t]{2}{*}{ Spin coating } & (1) $20 \mathrm{~s}$ & $500 \mathrm{rpm}, 100 \mathrm{rpm} / \mathrm{s}$ & $500 \mathrm{rpm}, 100 \mathrm{rpm} / \mathrm{s}$ \\
\hline & (2) $30 \mathrm{~s}$ & $1000 \mathrm{rpm}, 300 \mathrm{rpm} / \mathrm{s}$ & 3000rpm, 300rpm/s \\
\hline \multicolumn{2}{|l|}{ Soft bake } & $\operatorname{ramp}$ up $90^{\circ} \mathrm{C}, 2 \mathrm{~h}$ & ramp up $90^{\circ} \mathrm{C}, 2 \mathrm{~h}$ \\
\hline \multicolumn{2}{|l|}{ Relaxation } & $\begin{array}{l}\text { ramp down to RT } \\
\text { over night }\end{array}$ & $\begin{array}{l}\text { ramp down to RT } \\
\text { over night }\end{array}$ \\
\hline \multicolumn{2}{|l|}{ Exposure } & $180 \mathrm{~s}$ & $80 \mathrm{~s}$ \\
\hline \multicolumn{2}{|c|}{ Post exposure bake } & ramp up $75^{\circ} \mathrm{C}$, & ramp up $75^{\circ} \mathrm{C}$, \\
\hline \multicolumn{2}{|l|}{ Relaxation } & $\begin{array}{l}\text { ramp down to } \mathrm{RT} \\
\text { over night }\end{array}$ & $\begin{array}{l}\text { ramp down to RT } \\
\text { over night }\end{array}$ \\
\hline \multicolumn{2}{|c|}{ Development (PGMEA) } & flow-wash, $10 \mathrm{~min}$ & flow- wash, $45 \mathrm{~min}$ \\
\hline
\end{tabular}

* exposure, bake and development strongly depend on groove depths, here data are given for the example shown in Fig. 8.

and a pitch $f$ of $925 \mu \mathrm{m}$ within a total device area of the needle array of $3.95 \mathrm{~mm} \times 3.95 \mathrm{~mm}$, which is aligned with a center point symmetry in the overall back plate dimensions of $10 \mathrm{~mm} \times 10 \mathrm{~mm}$ after dicing. Subsequently, the exposed and baked layer $\boldsymbol{g}$ is developed supplying a continuous flow of propylene glycol methyl ether acetate (PGMEA) to the substrate surface. Step 4 shows the developed polymer needles $\boldsymbol{h}$ that are free-standing on the oblique surfaces of the v-grooves. An overview of the lithographic parameters for both the needles and the back plate is given in Table I. For the first level SU-8 processes resulting in the needles spin-coating parameters are chosen that form a $250-\mu$ m-thick SU-8 layer when the coating 


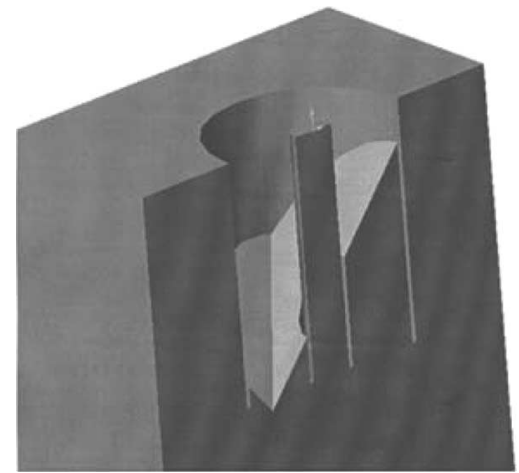

Fig. 3. Design drawing of the depression resulting from a 3-D nitride mask shaped in the silicon substrate in the form of two concentric cylinders.

is performed on a nonpatterned wafer. The total needle length prior to integration with the back plate is given by the extension of the resist into the v-grooves, which is here ca. $600 \mu \mathrm{m}$. The integration of the microfluidic back plate is described from step 4 onwards in Section V. The results of this process are presented in Section VI.

\section{PATtering OF 3-D Tip Shapes}

In this section, we present the formation of complex depressions by novel combinations of deep reactive-ion etching (DRIE) and wet etching processes using a set of three masks. Fig. 3 shows a schematic drawing of the desired 3-D shape using a silicon substrate with (100) orientation with a 3-D silicon nitride mask consisting of two concentric cylinders. Fig. 4 shows the sequence of processing steps leading to arrayed, inverted tip shapes in the substrate surface on an equidistant grid. The process starts with a standard (100) silicon substrate $\boldsymbol{a}$ in step 1. Deep dry etching is performed transferring the photoresist mask $\boldsymbol{b}$ (mask 1) to the silicon using established $\mathrm{SF}_{6}$-ICP-cryogenic directional etching (DRIE) with an etchrate of up to $2 \mu \mathrm{m} / \mathrm{min}$ [39]. Depending on the length of the required tip the etching time is tuned. To achieve the presented needle tips of this paper, we chose an etching depth $c$ of $50 \mu \mathrm{m}$. A trench of width $\boldsymbol{d}(2 \mu \mathrm{m})$ is filled by applying nitride deposition process for standard low-stress low-pressure chemical vapor deposition (LPCVD) silicon-rich nitride ( $\mathrm{SiRN}$ ). The trench width is a critical design parameter, i.e., with a $2-\mu$ m-wide trench and an achievable aspect ratio of 25 , the maximal needle shaft length that can be replicated from this type of silicon mold is, therefore, $50 \mu \mathrm{m}$. The design parameters are further discussed in Sections VI and VIII. The gaps are filled and the substrate is covered with the nitride in step 2 of Fig. 4, resulting here in a $1.3-\mu \mathrm{m}$-thick nitride layer on the plane of the substrate. Lithography is performed in step 3, which transfers the layout of the second mask (mask 2) to the nitride layer by standard parallel plate plasma etching in $\mathrm{CHF}_{3} / \mathrm{O}_{2}$ [40]. The patterned nitride $e$ will function as a mask in the subsequent anisotropic $\mathrm{KOH}$ etching process. By means of aligned lithography and the application of the DRIE process in step 4, the third mask is transferred to the silicon. The diameter and depth of this auxillary feature $f$, as well as its alignment within the outer needle boundary are critical design rule parameters, which allow to create the unique

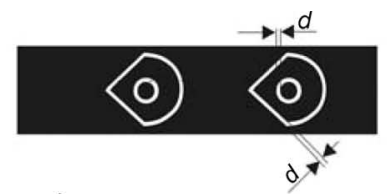

Top view

through mask 1 $b$

1

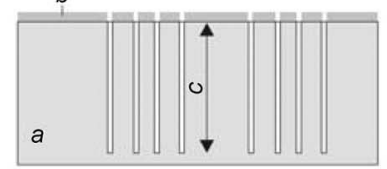

2
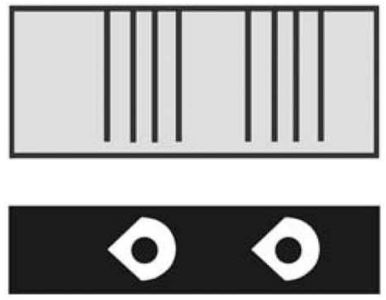

3
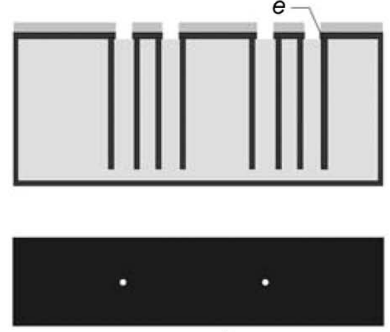

4

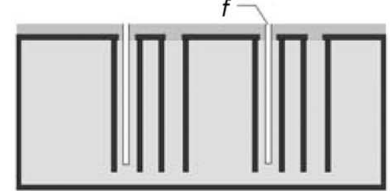

5

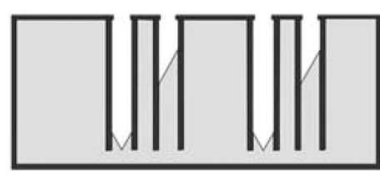

6
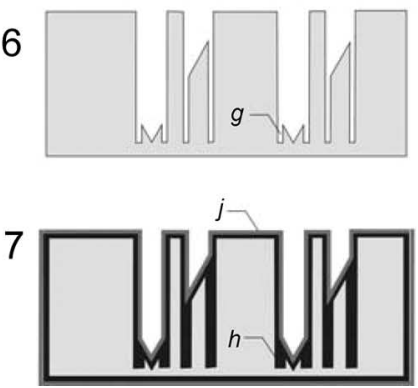

OLIN907-12 standard lithography; postbake; DRIE.

Standard wafer cleaning SiN deposition.

Top view

through mask 2

OLIN907-12 standard lithography; postbake; SiN-RIE.

Top view

through mask 3

OLIN907-12 standard lithography; postbake; DRIE.

Wet anisotropic etching.

SiN removal; cleaning

SiN deposition: poly-Si deposition
Fig. 4. Processing steps for complex mold. The shape in the silicon is the negative pattern of the intended needle tip with a microfluidic conduit.

3-D tip shape, for example, as depicted in Fig. 3. The auxillary feature assists the anisotropic $\mathrm{KOH}$ wet etch process starting the etching from the top and from a point below the substrate surface simultaneously through the auxillary feature $f$. The depth of the hole $f$ will determine the maximal needle tip length after anisotropic etching that starts from this point in the substrate.

To avoid that the (111) surfaces of the silicon crystal lattice run below the nitride filled trenches during creation of the tip during anisotropic $\mathrm{KOH}$ etching the DRIE depth of this 

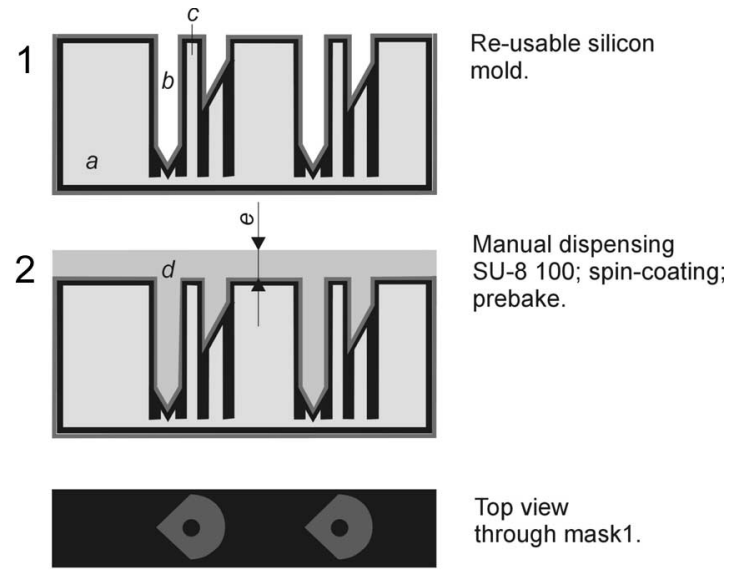

Top view

through mask1.

3
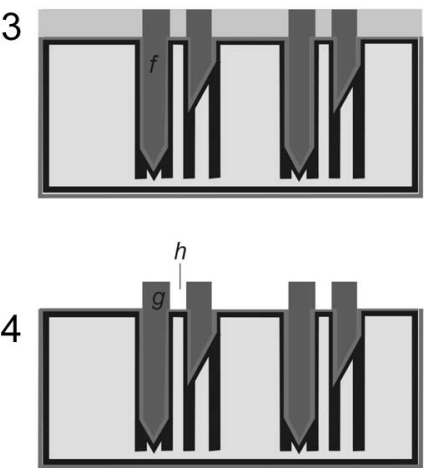

Circulating

flow development.

Fig. 5. SU-8 replication process with subsequent lithographic patterning for increasing the shaft length and integration of the back plate on top of the prepatterned silicon substrate that is shown in Fig. 4.

auxillary hole has to be chosen less deep than that of the trenches. By removal of the photoresist and subsequent cleaning in $\mathrm{HNO}_{3}$ the substrate is prepared for step 5, the anisotropic $\mathrm{KOH}$ etching. Step 6 presents the resulting shape after removal of the nitride. Stripping the mask and thorough cleaning of the substrate with a standard cleaning process developed at Radio Corporation of America, so called RCA clean, and $\mathrm{HNO}_{3}$ is a commonly applied good laboratory practice rule prior to any additional LPCVD process after $\mathrm{KOH}$ etching of silicon but leaves superfluous trenches $\boldsymbol{g}$ behind. To make the structure reusable for the subsequent replication of the silicon features, which is preferred when a relatively expensive and complex mold forming process is used, here, LPCVD-SiRN $\boldsymbol{h}$ is deposited to fill the remaining trenches and cover the silicon device. A layer $\boldsymbol{j}$, e.g., LPCVD deposited polysilicon, can be optionally applied. This additional layer allows removing a replica from the mold in the subsequent replication process of the complex shape by sacrificial layer etching against the SU-8 resist. Finally, step 7 in Fig. 4 depicts the patterned and smoothened surface.

Fig. 5 describes the continuation of the replication process applying lithographic molding. Step 1 shows the substrate $\boldsymbol{a}$, which was processed according to the description given in Fig. 4 above. This substrate contains depressions $\boldsymbol{b}$ and high aspect-ratio features $c$ that form the inverted shape of a needle tip. The combination of depressions and prismatic features $c$ will result in a hollow needle tip when the shape is replicated into a polymer.
In step 2, the photosensitive molding material $\boldsymbol{d}$ was applied gaining a thickness $e$ of $250 \mu \mathrm{m}$ by spin-coating. In step 3, the mask layout (mask 1) is transferred to the polymer applying the process as listed in Table I of the previous Section III. Variation in the depth of the depression might require optimization of lithographic exposure and development parameters to meet high pattern fidelity.

After lithography the exposed and baked pattern $f$ extends into the depressions. Development of this pattern results in the lithographic extension of shafts $\boldsymbol{g}$ and through-holes $\boldsymbol{h}$ on top of the prismatic features in the mold master by aligned lithography in step 4. The shafts of this type of needle tips can be also directly integrated with a microfluidic back plate in step 2, however, to further increase the shaft length an interconnecting feature like a back plate or a microrail (see Section VI for results) is preferable integrated by first finalizing the process sequence depicted in Fig. 5 and subsequently using the multilayer process to be able to extend the needle length as described in Section V.

\section{BACK Plate Integration}

To obtain an array of polymer needles a two level lithographic process is applied to both of the technological routes described in Sections III and IV. Fig. 6 shows the various steps of the microfluidic back plate integration in detail. Step 1 continuous the process of Sections III and IV, respectively, by dispensing a nonphotosensitive filling layer $\boldsymbol{a}$ into the free-standing needle features $\boldsymbol{b}$. Specific care must be taken that this polymer, e.g., nonphotosensitive SU-8 epoxy resin, does not flow on top of the shaft ends of the needles. To realize such a defined volume dispensing of the polymer, we apply droplet dispensing by micropipettes distributed across the wafer surface. The thickness $c$ of this filling layer, together with the depth of the depressions, defines the final length of the microneedles. In step 2, a second layer of photosensitive polymer $\boldsymbol{d}$ is applied. This layer is lithographically defined by alignment of the back plate mask (mask 1) to the needle features formed in the first SU-8 layer, which is depicted in step 3. The process parameters for the back plate lithography are listed in Table I of Section III for the example of a $200-\mu \mathrm{m}$-thick layer. The design contains access holes $\boldsymbol{e}$, which assist in the process of development and release.

Depending on a specific application the back plate thickness and the mask layout can be modified, however, process variations then require reoptimization of lithographic parameters. Step 4 combines the development of the pattern of the back plate and the removal of the filling layer through the additional holes in the back plate hence gaining an array $f$ of interconnected microneedles. The lithographic process in steps 3 and 4 also allows integrating additional features at the needle shafts as demonstrated by connecting the needles to a microrail feature (shown in Fig. 12 of Section VI). Alternatively, the second level process can be used for increasing the length of the needle shafts. Step 4 presents an integrated platform containing microneedles with microfluidic through-holes for both technological routes (A) and (B). Applying the sacrificial layer etching method, e.g., using polysilicon, the microneedle array can be released by etching the polysilicon selectively 

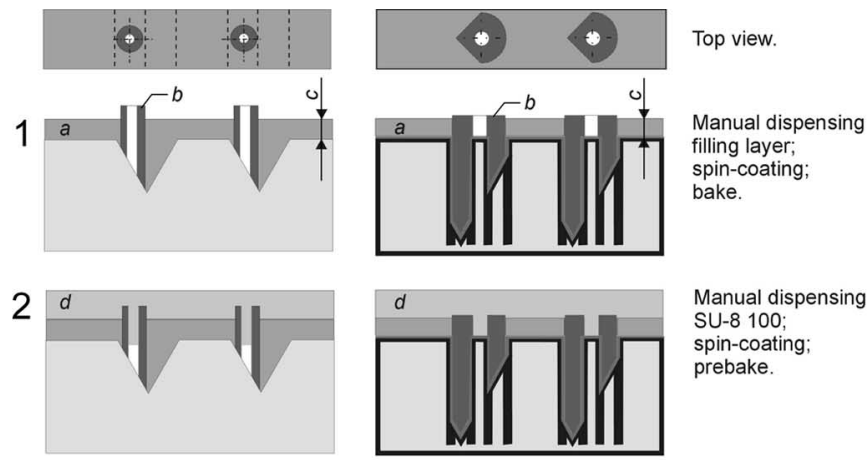

\section{Manual dispensing SU-8 100; spin-coating; prebake.}
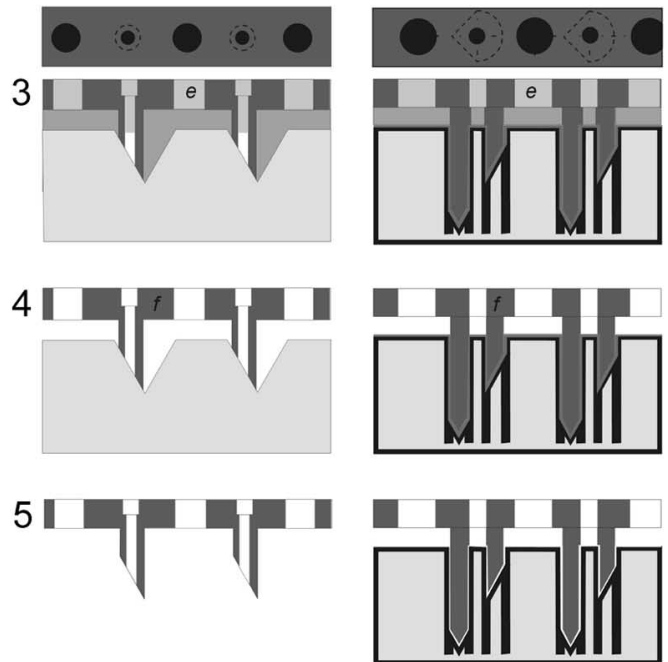

Release etch (A) lost mold;

(B) sacrificial layer etch.

6

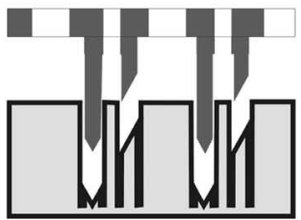

(b)

Fig. 6. Multilevel SU-8 process with subsequent lithographic forming of a microfluidic back plate. (a) Process performed on simple v-grooves, (b) process performed on 3-D micromachined depressions in the silicon substrate.

against nitride and SU-8 in a standard $25 \mathrm{wt} . \% \mathrm{KOH}$ solution at $74{ }^{\circ} \mathrm{C}$. Optionally, the sacrificial layer can be used for the simple shape depicted in route (A), however, the lower processing costs for a v-grooved substrate by anisotropic wet etching may allow to skip these process steps.

The design of the access holes was chosen according to the case that no additional filling layer during back plate processing would be used and the removal process has to occur through a narrow gap over quite a long distance. The release etching time over a line distance of ca. $5.5 \mathrm{~cm}$ (refers to a distance from the edge of a 4-in substrate to its middle) is calculated using a linear extrapolation of the measurement for polysilicon etching in a nanochannel of Berenschot et al. [41], (which leads to an underestimation, since the etch length deviates from linear behavior for very long etching times due to mass transport limitations [42]). For the case of a fully SU-8 encapsulated substrate surface, the polysilicon release time would result in approximately $800 \mathrm{~h}$. This result is not only intolerable for either research or production but it could also lead to

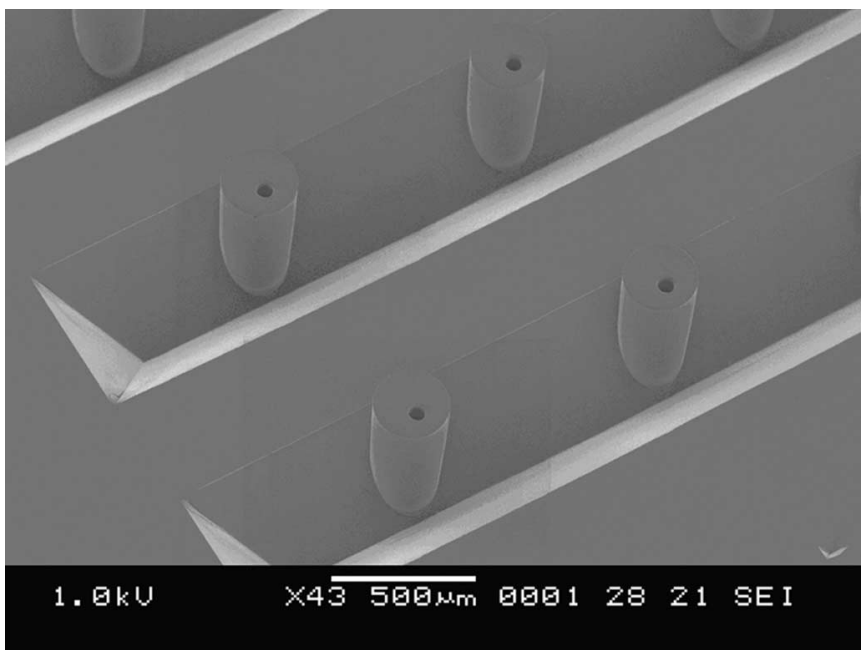

Fig. 7. Scanning electron micrograph at $30^{\circ}$. Lithographically formed SU-8 needles on top of v-grooves.

degradation of the used polymer. Therefore, the access holes were positioned equidistant in between every needle reducing the release distance to approximately $600 \mu \mathrm{m}$. The polysilicon release should be possible within a few minutes. Applying an extra polymer filling layer, $\mathrm{KOH}$ can move underneath of the SU-8 back plate by capillary forces quickly and the diffusion limited process is restricted to the area on which the needle tip is anchored on the substrate thus a distance of ca. $125 \mu \mathrm{m}$ (radius of the needle) has to be released. In this case, the dissolution rate of the polymer filling using a $200-\mu \mathrm{m}$ layer thickness is the restricting factor for the design of the access patterns $e$ (see Fig. 6). For example, if a trench system of $600-\mu \mathrm{m}$ width is superimposed thus that it creates a raster pattern around the needle arrays $(10 \mathrm{~mm} \times 10 \mathrm{~mm})$ the etching distance from the substrate circumference to the middle of the array increases to approximately $5 \mathrm{~mm}$. Here, the dissolution rate of the filling layer $(12.5 \mu \mathrm{m} / \mathrm{min})$ restricts the release process to ca. $7 \mathrm{~h}$ (worst case). Using the equidistant holes, the removal process is approximately nine times faster (45 $\mathrm{min})$.

\section{FABRICATION RESUltS}

Section III describes a process sequence leading to arrayed microneedles fully formed by lithography on a prepatterned substrate, which contains in its simplest form only v-grooves. Fig. 7 depicts an example of an array of needles being formed on the slope of such v-grooves. Their total height depends on the resist thickness extending onto the v-groove. We did not measure the height of the needles on the v-grooves in this intermediate lithographic step exactly but from the SEM picture, we can estimate a height of more than $500 \mu \mathrm{m}$. Applying the process sequence listed in Section $\mathrm{V}$, the arrayed microneedles are connected to the back plate. A result of this process is shown in Fig. 8, while details of the tip are shown in Fig. 9. These integrated needles have a final needle shaft length of $430 \mu \mathrm{m}$ as determined from Fig. 9(a).

Section IV describes the fabrication of a tip by molding from a complex 3-D shape. This process is very sophisticated and the full details of achievements are still under discussion. Fig. 10 depicts molds of different designs. It is of outmost 


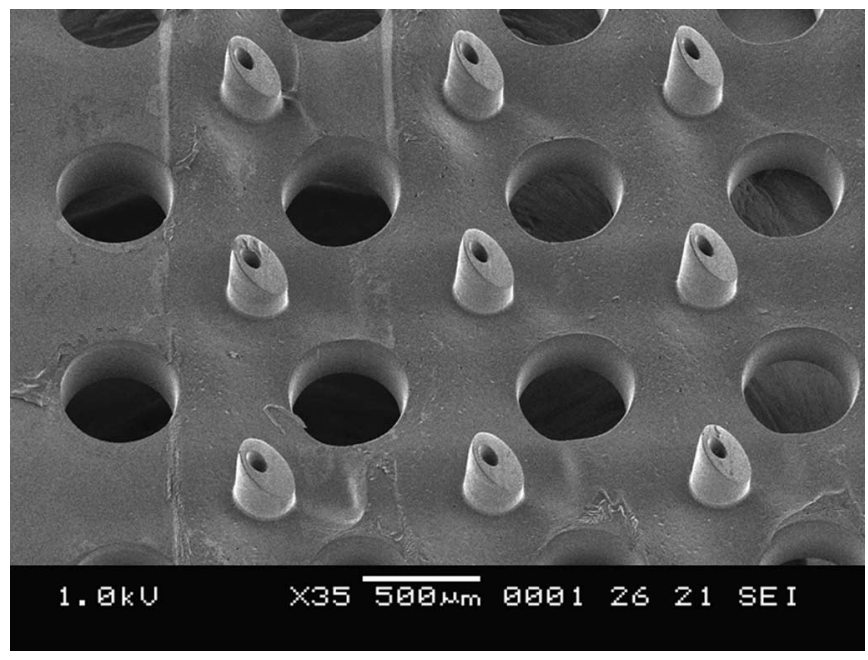

Fig. 8. Array of needles achieved by the lithographic molding process depicted in Figs. 2 and 6(a).

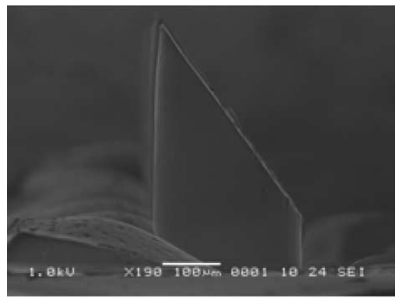

(a)

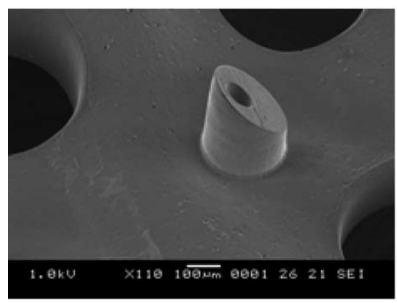

(c)

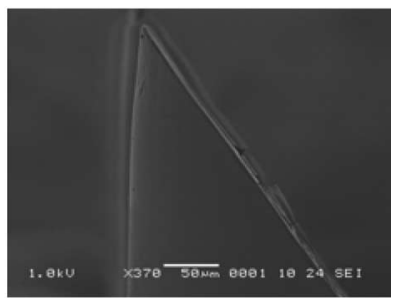

(b)

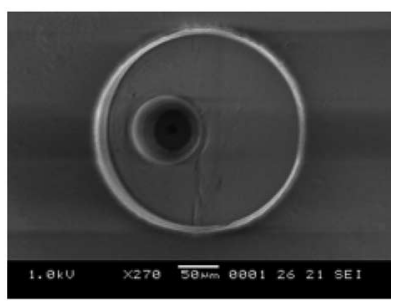

(d)
Fig. 9. SEM picture of an SU-8 microneedle tip. (a) Profile of one of the needle tips within an array of 25 needles. (b) Close-up of the tip. (c) Bird's-eye view of a needle. (d) Top view of the same needle as in (c).

importance that the silicon nitride layer that fills the trenches is pinhole free and has a high edge coverage otherwise the defects in the mask can cause disastrous mold defects. Fig. 10 also shows that the trench width and nitride layer thickness still need optimization to achieve a full coverage of the trench and thus no remaining superfluous gaps. Despite the encountered problems during fabrication a proof of principle for SU-8 lithographic molding using complex silicon shapes was achieved.

An example of the faithful replication from the mold structure in Fig. 10(b) is depicted in Fig. 11 revolving the inverted shape of the mold, clearly showing the replicated crystal planes. A further discussion of the process criteria for anisotropic silicon etching for this application is given in Fig. 16 in Section VIII.

Once more the molding process can be combined with the lithographic definition of additional features. Here, Fig. 12(a) shows the example of molded microtips connected to a microrail network, which connects all needle shafts and therefore

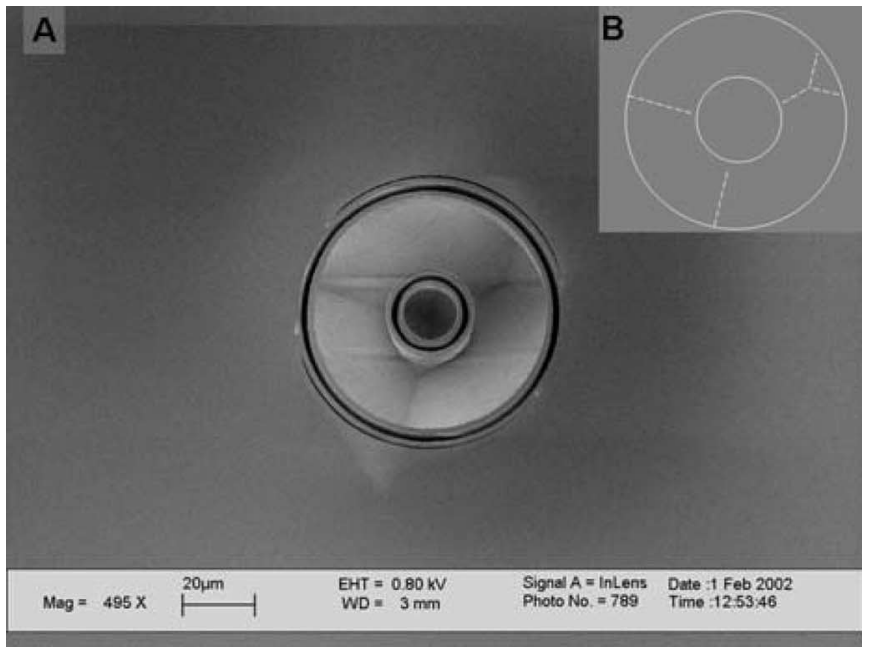

(a)

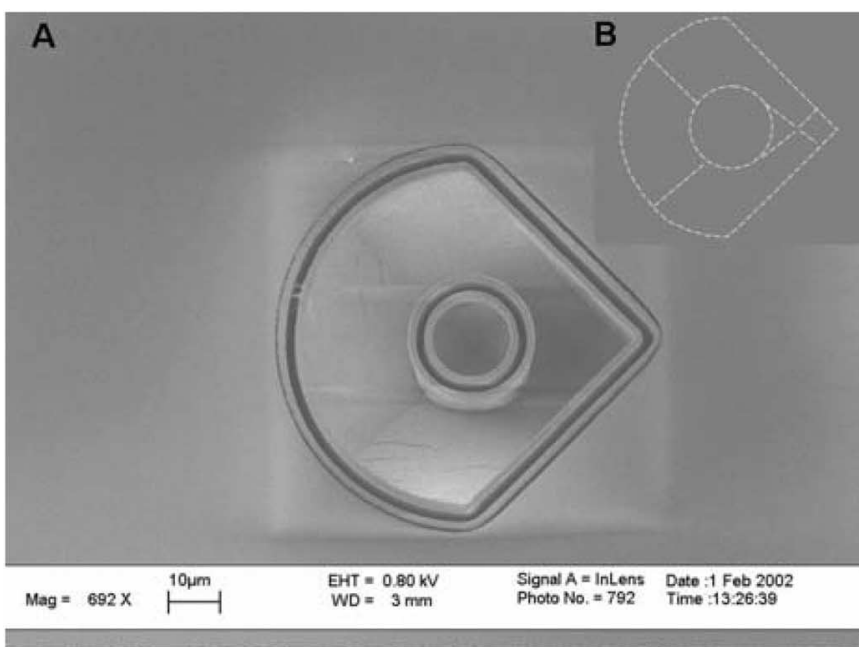

(b)

Fig. 10. SEM pictures of silicon mold (A) using (a) a concentric circular mask and (b) a more complex asymmetric mask design that leads to an off-centered microfluidic conduit in the needles fabricated according to the process depicted in Fig. 5. To guide the eye insets (B) show the geometry of intersections of $\langle 111\rangle$ crystal planes in the silicon. The silicon nitride mask was removed leaving the trenches visible in the moldstructure.

allows release from the substrate as an array instead of single needles in solution.

This lithographic procedure can either be used to extend the needle shafts or to develop a full microfluidic platform suggested in the concept by the integration of a solid back plate. On the other hand, the microrail structure demonstrates that needles can be connected in a way that supports individual micromechanical displacements of needles or rows of needles against each other by smart integration of tension bar microstructures. This is a specific property of the multilayer process and can offer a larger impact of this technology route in MEMS, e.g., in innovative designs for individual positioning of microneedles within an out-of-plane neuroprobe device. Fig. 12(b) shows a close-up of the well-defined replicated features of the tip connected to the microrail. In terms of integrated functionality the simple microneedle device as depicted in Fig. 8 was also tested for its application as a sample collector in medical diagnostics, which is described in more detail in Section VII. 


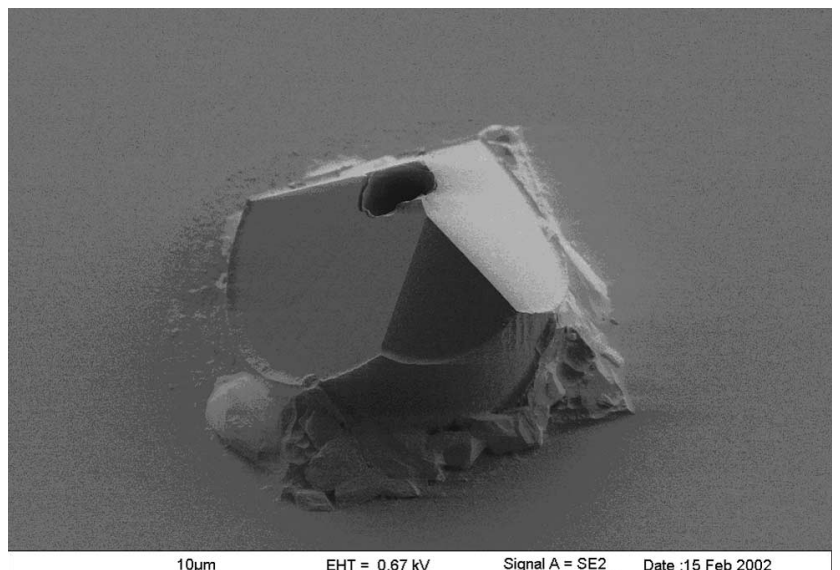

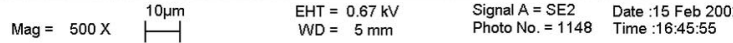

Fig. 11. SEM pictures of a tip fully replicated by molding using SU-8 as filling material (tip shows the surfaces inherent to single crystalline silicon etching). Outer diameters are $95 \mu \mathrm{m}$, and through-hole diameter is $20 \mu \mathrm{m}$. Here, the tip extends from a solid plate by curing of the resist material after spinning. The irregular defects around the needle shafts are due to imperfect mold preparation and remain as a part of mold optimization.

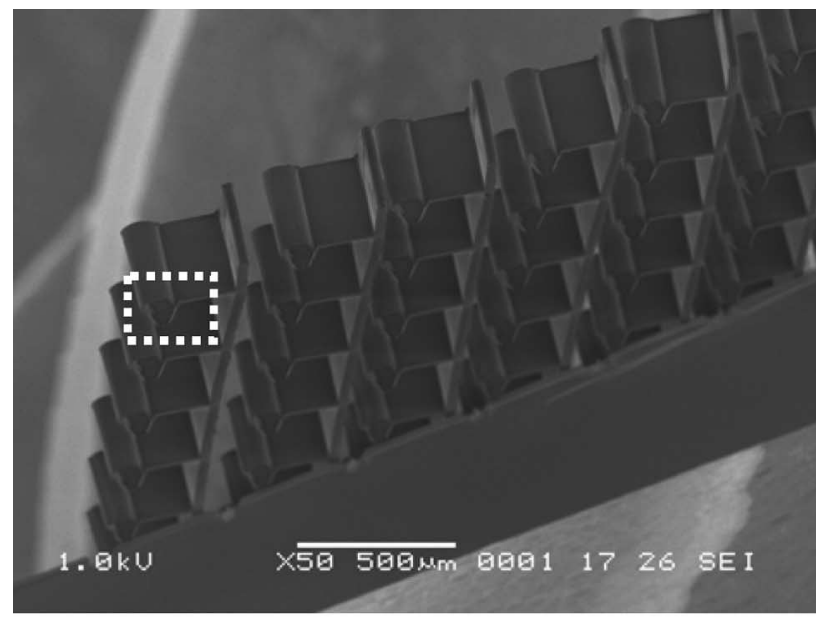

(a)

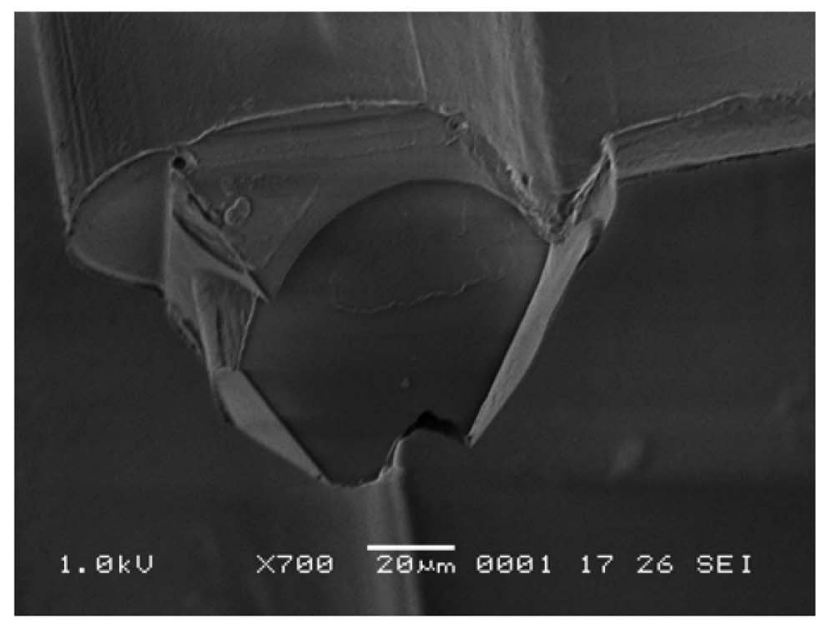

(b)

Fig. 12. (a) SEM picture of an array of SU-8 microstructures with a lithographically molded tips connect to a microrail interconnecting all tips. (b) Close-up of the tip shape as given in the white mark in (a).

\section{Microfluidic Performance Tests}

Before the analytical performance of the SU-8 microneedle patch can be tested, the through-holes within the SU-8 have to be inspected and need to function as fluid conduits. Although optical microscopy shows that the conduits were opened after resist development a fluidic assay using fluorescent dye is performed. Fig. 13 demonstrates that the microneedles can be filled. To be able to visualize the fluidic transport within the microneedle conduit at the microscope in-real time a $100 \mu \mathrm{l}$ droplet of aqueous dye solution was applied from the back of the patch.

Although optical dispersion within the device hampers the full inspection of the conduit geometry, microfluidic transport of sample takes place spontaneously by capillary force. However, the aqueous fluid also withdraws quickly, which can be most likely explained by evaporation of the droplet that had been placed on the back plate. Repeating the same experiment with a complex fluid such as blood that was taken from a conventionally performed finger-stick and stopped from coagulation, the blood sample applied now from the microneedle tip remained securely inside the microneedle conduits (see inset of Fig. 15). This demonstrates the feasibility of using microneedle arrays as a blood transfer device to an appropriate analytical technique, including also off-line methods such as, for example, mass spectroscopy.

It is possible that a patient uses the microneedles to collect body fluid and then transfers the sample to a microfluidic diagnostic platform. For that purpose, a microchip capillary electrophoresis (CE) set-up suitable for Point-of-Care blood measuring applications can be used [43].

Such a device is schematically depicted in Fig. 14. The reservoir for sample transfer was filled with water assisting field amplified stacking, while the remaining reservoirs and the channel network in the microchip-CE device were filled with background electrolyte.

For the analytical performance test of the SU-8 microneedle patch as sampler for state-of-the-art microchip-CE, we verified for the first time that a volume as small as the volume hold by six microconduits is sufficient for analysis. Here, the six conduits were manually filled with a pipette dispensing a sample volume of approximately $3 \mathrm{nl}$ onto the tip of each of the microneedles modeling the in vivo situation of, e.g., transdermal sampling. Sample transfer from the patch to the analysis chip was first investigated for an aqueous calibration solution containing alkali metal ions equivalent to blood plasma and lithium as a drug model compound. For comparison to a realworld sample, a blood sample was also manually transferred by a pipette to the six conduits after thoroughly rinsing off the calibration sample in water. A glass microchip channel network with a cross section of approximately $45 \mu \mathrm{m} \times 8 \mu \mathrm{m}$ and a double-T injector layout was coated with polyacrylamide to suppress electroosmotic flow. A sample is loaded into the sample channel from the microneedle array by pinched injection. Subsequently, separation takes place in a microcolumn of $2-\mathrm{cm}$ length applying an electric field of $500 \mathrm{~V} / \mathrm{cm}$. A background electrolyte (buffer) of 30- $\mathrm{mM} \mathrm{NH}_{4} \mathrm{Ac} / 30-\mathrm{mM} \mathrm{HAc}$ with 5-mM 18-crown- 6 as an additive and end-column conductivity detection is used to carry out the determination of the alkaline ion 

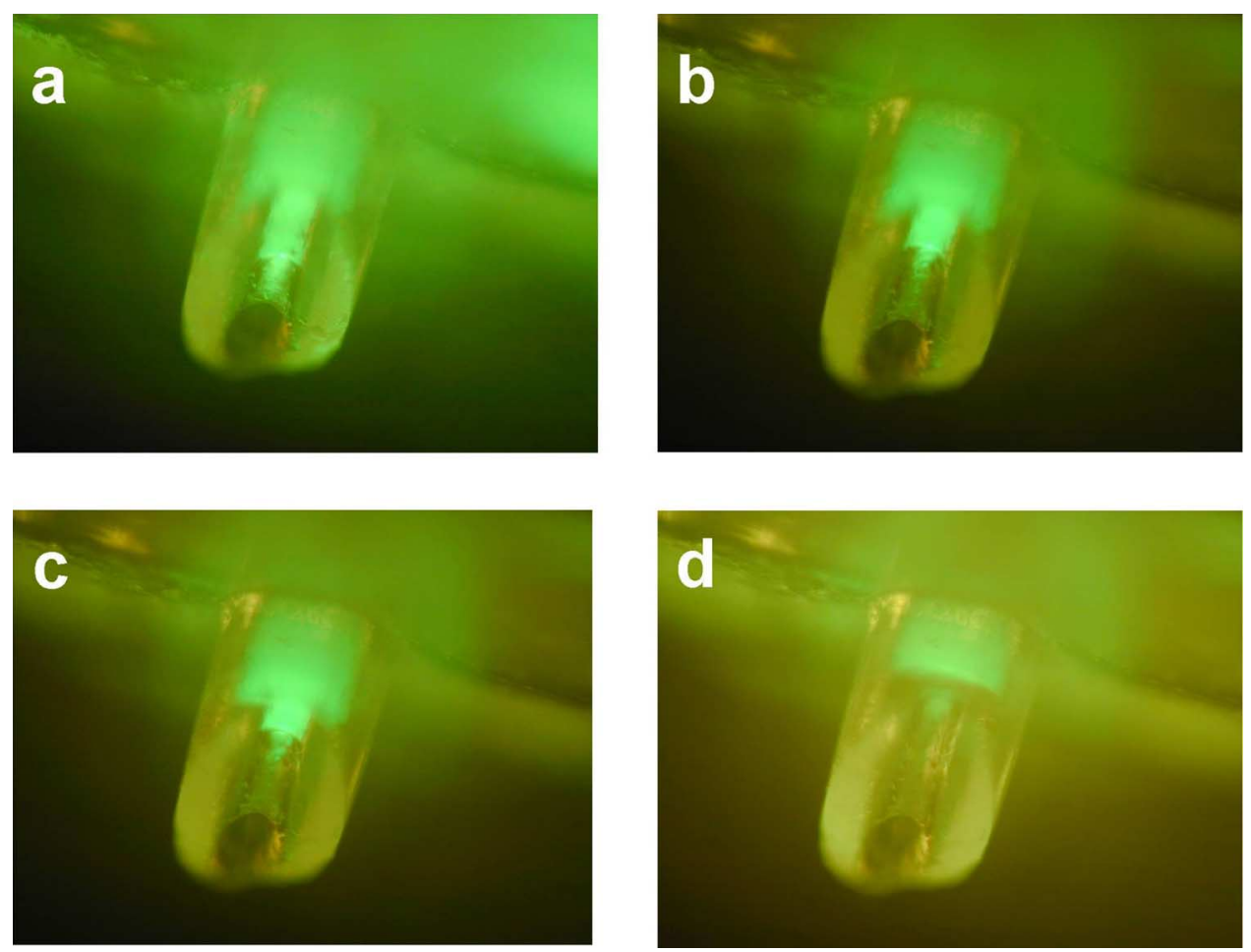

Fig. 13. Sequence of fluorescent dye images after deposition of a droplet onto the back plate of the patch. (a) The needle fills spontaneously by capillary force. (b)-(d) Sample withdraws from the capillary.

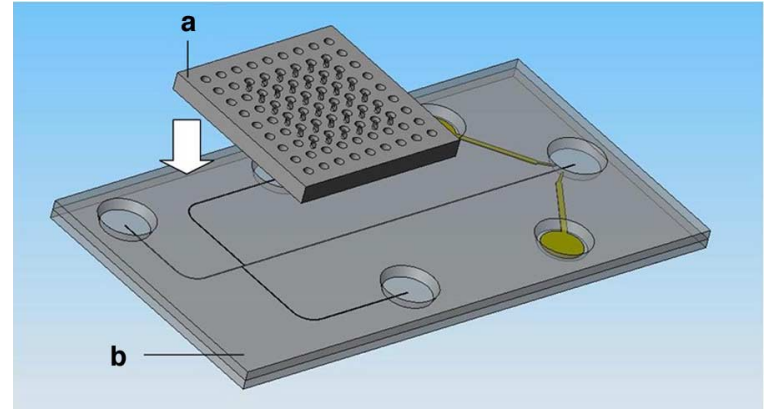

Fig. 14. Concept of lab-on-chip needle array hybridly integrated medical device. Needle array $\boldsymbol{a}$ positioned above sample inlet of CE chip $\boldsymbol{b}$.

concentrations in the consequently formed zones. In Fig. 15, the electropherogram of the calibration sample of 4-mM potassium, 140-mM sodium, 2.5-mmol/L calcium, 1-mM magnesium, and $1-\mathrm{mM}$ lithium diluted from the chloride salts of each of the ions in water is compared to the electropherogram of a whole blood sample. In both of the electropherograms potassium, sodium, and magnesium can be identified. At the used conditions the mobility of calcium overlaps with the mobility of sodium, therefore, calcium cannot be separated from the sodium, here. The electropherogram of the calibration solution shows the drug model compound lithium as an additional peak, which is naturally not present in the blood of the volunteer A more thorough investigation of the sample interface and the microchip-CE principle was carried out by us using a glass capillary as a sample collector and comparing its performance with a silicon micromachined needle array, of which the results were presented by us elsewhere [44]. However, these
Time in $\mathbf{s}$

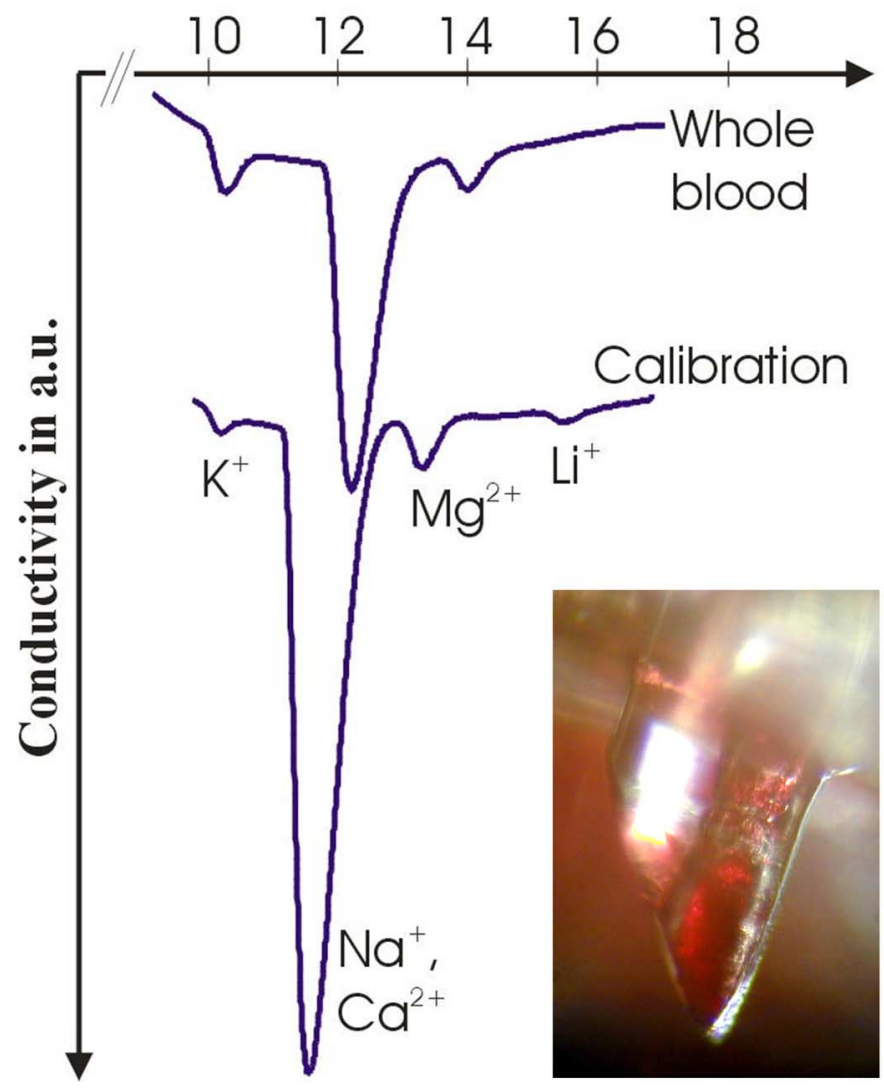

Fig. 15. Microchip CE of blood and calibration sample through an SU-8 microneedle patch. The inset shows the collected blood sample inside of a microneedle. 

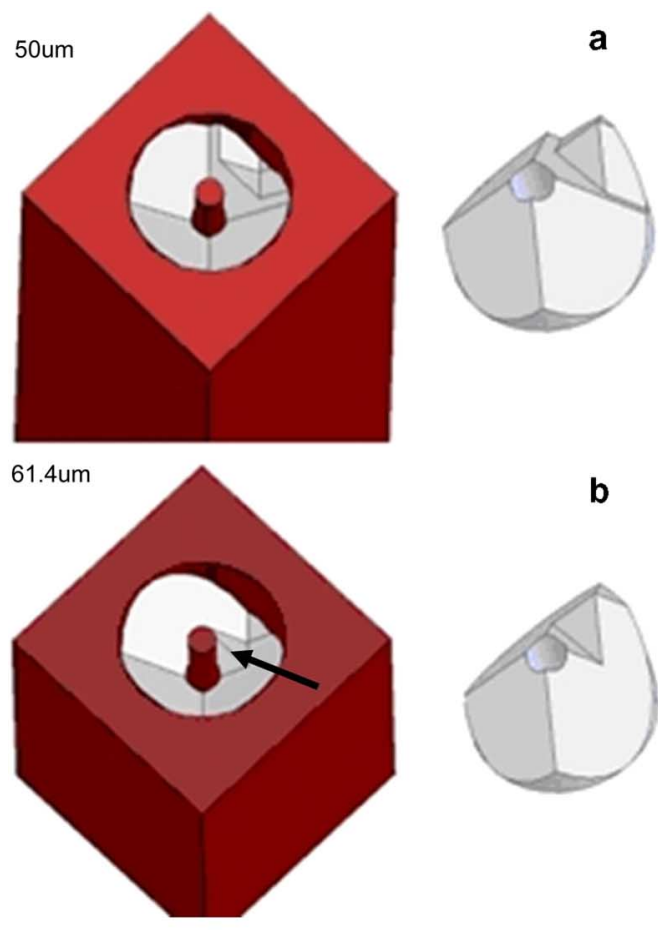

b
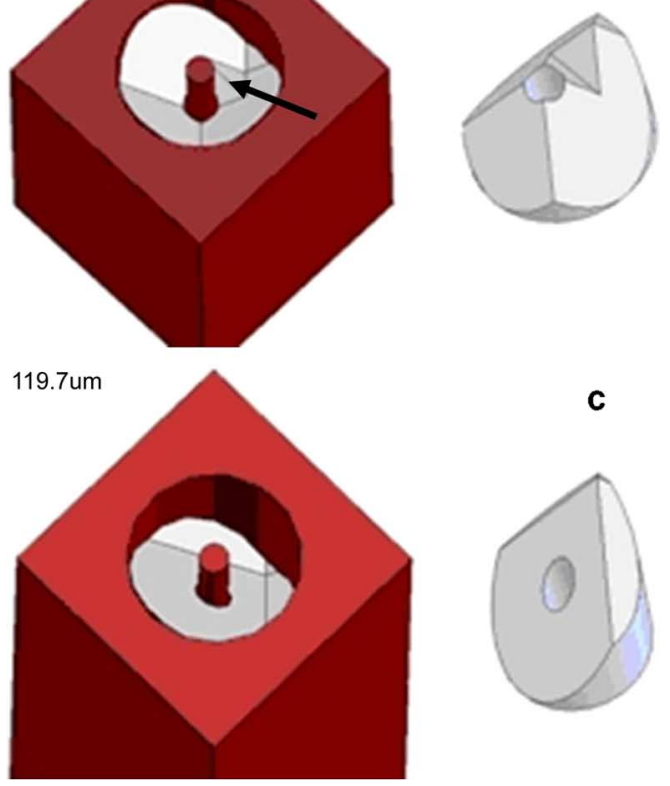

C

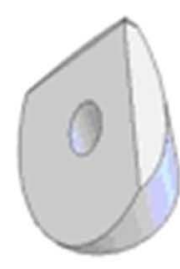

Fig. 16. Three-dimensional drawings assisting the design process showing the shape of the mold (left) and the resulting tip (right) for different etch depths of the auxillary hole of (a) $50 \mu \mathrm{m}$, (b) $61.4 \mu \mathrm{m}$, and (c) $119.7 \mu \mathrm{m}$, respectively.

results presented here show that SU-8 needle patches are a suitable sample transfer device and further investigation to optimize a fully integrated analytical system is, therefore, highly recommended.

\section{DISCUSSION}

Performing high-aspect-ratio SU-8 lithography on a sloped surface will lead to needle heights of $500 \mu \mathrm{m}$ and more. The combination of DRIE and $\mathrm{KOH}$ etching starting from a point below the silicon surface leads to various designs of complex 3-D shapes that can offer exciting new possibilities for applications.

Using the complex mold process, the geometrical definition of the auxillary feature is the key to receive the desired needletype shape as described in Section IV. The (111) crystal plane on which the auxillary feature stops at the lowest point in the mold has to meet with the (111) crystal planes etched from the top of the substrate. Fig. 16 shows 3-D drawings that assist in understanding the development of crystal planes during the etching process in $\mathrm{KOH}$. The figures are only based on a geometrical model and do not fully recapitulate the final shapes. In Fig. 16(b), for example, the region marked with the arrow will eventually etch from the obstruction in the middle of the opening. For an etch depth of the auxillary hole larger than $120 \mu \mathrm{m}$ [Fig. 16(c)], the planes will meet according to the design rules in anisotropic silicon bulk etching. Unfortunately, the tip height achieved from the mold presented in Fig. 11 was restricted by the aspect ratio of the current DRIE process and is therefore limited to an approximate needle tip length of $80 \mu \mathrm{m}$. To achieve a needle length for a specific purpose in sampling applications, however, this tip length can be increased using a photolithographic multilayer process as suggested in Section $\mathrm{V}$ which was demonstrated by the addition of a structural element, here a microrail. When this lithographic resist material is considered also as biocompatible and is approved by FDA, this process can be very attractive to make tips from specific materials e.g., for therapeutic purpose or materials that take part in a sample pretreatment for bioanalytics. A tip fabricated by replication is also not sensitive to backscattering from the oblique substrate walls which can be a problem in the simplified process route described in Section III. The micromolding concept described in Section IV has therefore clear advantages compared to the simplified process described in Section III. SU-8 already has been introduced in many biomedical related material studies as a material with a high potential for biocompatibility.

The high pattern fidelity in our new lithographic micromolding process transferring a pattern of such complex shape as a needle tip into a replica has been normally only attributed to processes such as LIGA that use hot-embossing or injection mold inserts being formed by high-cost X-ray lithography and electroplating from a nickel bath. The results demonstrated in this paper present that complex polymer features can be successfully fabricated by batch-type lithographic molding on preprocessed silicon substrates. An additional advantage of using the mold fabrication introduced here is its compatibility with standard MEMS process lines.

In respect to the diagnostic results, these are truly preliminary and only demonstrated by hybrid-integration of microneedle and diagnostic chip. A thorough investigation of sample interface characteristics to a $\mathrm{CE}$ chip has been performed by us elsewhere [16]. Despite that microneedle array applications are practically in their infancy, the potential of microneedle patches in medical Point-of-Care applications such as for the determination of alkaline ions in whole blood is demonstrated here. A generic analytic technique such as $\mathrm{CE}$ as introduced in combination with microneedles in this paper can mark a future breakthrough in medical disease management.

A final point of discussion is the broader impact of such technique to the field of MEMS technology. Not only medical devices can benefit from the lithographic molding technique of such a unique tip shape as introduced in this paper. Other highly interesting fields of applications are microinjector structures such as used in ink-jet printing, electrospray nozzles and, e.g., dosing nozzles for hydrodynamic focusing in microfluidic chemical reactors and cell analysis devices. One example for such type of microchimney structure has been already discussed by Wolff et al. [45] for the hydrodynamic focusing of cell suspensions, while off-centered introduction of the fluid stream 
such as offered by the needle design in this paper can have additional benefits for these kinds of systems.

\section{CONCLUSION}

Two new fabrication processes have been described which incorporate the pattern transfer by lithographic molding using preprocessed substrates. The combination of sophisticated $\mathrm{KOH}$ etching with DRIE allows decoupling the fabrication of a unique tip shape from the fabrication of a needle shaft. The processes were demonstrated for the integration of microneedle arrays with microfluidic lab-on-chip functions.

Finally, it was shown that SU-8 microneedles can be hybridly coupled to microchip capillary zone electrophoresis for the measurement of inorganic ions in blood. Other potential medical applications of these patch-type microneedle devices can be found in tissue biopsy and drug delivery.

\section{ACKNOWLEDGMENT}

The authors would like to thank B. Otter and R. Duwel, both of $\mathrm{MESA}^{+}$, University of Twente, for their SEM work and technical drawings, respectively; S. Y. Yeshurun and M. Hefetz, who have motivated this research at NanoPass Technologies, Ltd. and stimulated the discussions on polymer fabrication for microneedles in medical diagnostics; R. van't Oever, Micronit Microfluidics B.V., for many stimulating discussions on R\&D microfabrication processes; and H. Gardeniers, MESA ${ }^{+}$, University of Twente, for commenting on the manuscript.

\section{REFERENCES}

[1] K. D. Wise and K. Najafi, "Microfabrication techniques for integrated sensors and microsystems," Science, vol. 254, no. 5036, pp. 1335-1342, Nov. 1991.

[2] P. Griss and G. Stemme, "Side-opened out-of-plane microneedles for microfluidic transdermal liquid transfer," J. Microelectromech. Syst., vol. 12, no. 3, pp. 296-301, Jun. 2003.

[3] S. Chandrasekaran, J. D. Brazzle, and A. B. Frazier, "Surface micromachined metallic microneedles," J. Microelectromech. Syst., vol. 12, no. 3, pp. 281-288, Jun. 2003.

[4] H. J. G. E. Gardeniers, R. Luttge, E. J. W. Berenschot, M. J. de Boer, S. Y. Yeshurun, M. Hefetz, R. van't Oever, and A. van den Berg, "Silicon micromachined hollow microneedles for transdermal liquid transport," J. Microelectromech. Syst., vol. 12, no. 6, pp. 855-862, 2003.

[5] L. Lin and A. P. Pisano, "Silicon-processed microneedles," J. Microelectromech. Syst., vol. 8, no. 1, pp. 78-84, Mar. 1999.

[6] M. L. Reed and W.-K. Lye, "Microsystems for drug and gene delivery," Proc. IEEE, vol. 92, no. 1, pp. 56-75, Jan. 2004.

[7] D. V. McAllister, P. M. Wang, S. P. Davis, J.-H. Park, P. J. Canatella, M. G. Allen, and M. R. Prausnitz, "Microfabricated needles for transdermal delivery of macromolecules and nanoparticles: Fabrication methods and transport studies," Proc Nat. Acad. Sci. USA, vol. 100, no. 24, pp. 13755-13760, Nov. 25, 2003.

[8] B. Stoeber and D. Liepmann, "Fluid injection through out-of-plane microneedles," in Proc. 1st Annu. Int. Conf. Microtechnologies Med. Biol., Oct. 12-14, 2000, pp. 224-228.

[9] E. V. Mukerjee, S. D. Collins, R. R. Isseroff, and R. L. Smith, "Microneedle array for transdermal biological fluid extraction and in situ analysis," Sens. Actuators A, Phys., vol. 114, no. 2/3, pp. 267-275, Sep. 2004.

[10] C. Ahn, J. Choi, G. Beaucage, J. Nevin, J. B. Lee, A. Puntambekar, and J. Y. Lee, "Disposable smart lab-on-a-chip for point-of-care clinical diagnostics," Proc. IEEE, vol. 92, no. 1, pp. 154-173, Jan. 2004.

[11] S. Zimmermann, D. Fienbork, A. W. Flounders, and D. Liepmann, "Indevice enzyme immobilization: Wafer-level fabrication of an integrated glucose sensor," Sens. Actuators B, Chem., vol. 99, no. 1, pp. 163-173, Apr. 2004.
[12] H. Suzuki, T. Tokuda, T. Miyagishi, H. Yoshida, and N. Honda, "A disposable on-line microsystem for continuous sampling and monitoring of glucose," Sens. Actuators B, Chem., vol. 97, no. 1, pp. 90-97, Jan. 2004

[13] G. Kotzar, M. Freas, P. Abel, A. Fleischman, S. Roy, C. Zorman, J. M. Moran, and J. Melzak, "Evaluation of MEMS materials of construction for implantable medical devices," Biomaterials, vol. 23, no. 13, pp. 2737-2750, Jul. 2002.

[14] M. Stangegaard, Z. Wang, J. P. Kutter, M. Dufva, and A. Wolff, "Whole genome expression profiling using DNA microarray for determining biocompatibility of polymeric surfaces," Mol. Biosyst., vol. 2, no. 9, pp. 421-428, 2006.

[15] P. Zhang, G. Londe, J. Sung, E. Johnson, M. Lee, and H. J. Cho, "Microlens fabrication using an etched glass master," Microsyst. Technol., vol. 13, no. 3/4, p. 339, Feb. 2007.

[16] E. X. Vrouwe, R. Luttge, I. Vermes, and A. van den Berg, "Microchip capillary electrophoresis for point-of-care analysis of lithium," Clin. Chem., vol. 53, no. 1, pp. 117-123, Jan. 2007.

[17] J.-H. Park, S. Davis, Y.-K. Yoon, M. R. Prausnitz, and M. G. Allen, Micromachined Biodegradable Microstructures. 0-7803-7744-3/03/ $\$ 17.00$ 2003 IEEE.

[18] J.-H. Park, M. G. Allen, and M. R. Prausnitz, "Biodegradable polymer microneedles: Fabrication, mechanics and transdermal drug delivery," in Proc. 26th Annu. Int. Conf. EMBC, Sep. 1-5, 2004, vol. 1, pp. 2654-2657.

[19] M. Han, W. Lee, S.-K. Lee, and S. S. Lee, "3-D microfabrication with inclined/rotated UV lithography," Sens. Actuators A, Phys., vol. 111, no. 1, pp. 14-20, 2004.

[20] R. Turner, Y. Desta, K. Kelly, J. Zhang, E. Geiger, S. Cortez, and D. C. Mancini, "Tapered LIGA HARMs," J. Micromech. Microeng., vol. 13 , no. 3, p. $367,2003$.

[21] N. Matsuzuka, Y. Hirai, and O. Tabata, A Novel Fabrication Process of 3-D Microstructures by Double Exposure in Standard Deep X-Ray Lithography, 2004. IEEE, 0-7803-8265-X/04.

[22] S. J. Moon and S. S. Lee, "A novel fabrication method for microneedle array," in Proc. $\mu$ TAS 8th Int. Conf. Miniaturized Syst. Chemistry and Life Sci., T. Laurell, J. Nilsson, K. Jensen, D. J. Harrison, and J. P. Kutter, Eds., Malmö, Sweden, Sep. 26-30, 2004, pp. 360-362.

[23] C.-H. Lin, G.-B. Lee, B.-W. Chang, and G.-L. Chang, "A new fabrication process for ultra-thick microfluidic microstructures utilizing SU-8 photoresist," J. Micromech. Microeng., vol. 12, no. 5, pp. 590-597, 2002.

[24] A. P. Gadre, A. J. Nijdam, J. A. Garra, A. H. Monica, M. C. Cheng, C. Luo, Y. N. Srivastava, T. W. Schneider, T. J. Long, R. C. White, M. Paranjape, and J. F. Currie, "Fabrication of a fluidic encapsulated dermal patch using multilayered SU-8," Sens. Actuators A, Phys., vol. 114, no. 2/3, pp. 478-485, Sep. 2004.

[25] M. O. Heuschkel, L. Guérin, B. Buisson, D. Bertrand, and P. Renaud, "Buried microchannels in photopolymer for delivering of solutions to neurons in a network," Sens. Actuators A, Phys., vol. 48, no. 1-3, pp. 356361, May 1998

[26] Y.-J. Chuang, F. G. Tseng, J. H. Cheng, and W.-K. Lin, "A novel fabrication method of embedded micro-channels by using SU-8 thick-film photoresists," Sens. Actuators A, Phys., vol. 103, no. 1/2, pp. 64-69, Jan. 2003.

[27] R. J. Jackman, T. M. Floyd, R. Ghodssi, M. A. Schmidt, and K. F. Jensen, "Microfluidic systems with on-line UV detection fabricated in photodefinable epoxy," J. Micromech. Microeng., vol. 11, no. 3, pp. 263-269, 2001.

[28] J. Zhang, K. L. Tan, G. D. Hong, L. J. Yang, and H. Q. Gong, "Polymerization optimization of SU-8 photoresist and its applications in microfluidic systems and MEMS," J. Micromech. Microeng., vol. 11, no. 1, pp. 20-26, Jan. 2001

[29] H. Sato, T. Kakinuma, J. S. Go, and S. Shoji, "In-channel 3-D micromesh structures using maskless multi-angle exposure and their microfilter application," Sens. Actuators A, Phys., vol. 111, no. 1, pp. 87-92, Mar. 2004.

[30] R. Trichur, S. Kim, X. Zhu, J. W. Suk, C.-C. Hong, and C. H. Ahn, "Development of plastic microneedles for transdermal interfacing using injection molding techniques," in Proc. Micro Total Anal. Syst., 2002, vol. 1 , pp. 395-397.

[31] M. Despont, H. Lorenz, N. Fahrni, J. Brugger, P. Renaud, and P. Vettiger, "High-aspect-ratio, ultrathick, negative-tone near-UV photoresist for MEMS applications," in Proc. IEEE 10th Annu. Int. Workshop Micro Electro Mech. Syst., 1997, pp. 518-522.

[32] H. Lorenz, M. Despont, N. Fahrni, J. Brugger, P. Vettiger, and P. Renaud, "High-aspect-ratio, ultrathick, negative-tone near-UV photoresist and its application for MEMS," Sens. Actuators A, Phys., vol. 64, no. 1, pp. 33-39, Jan. 1998. 
[33] S. Linder, H. Baltes, F. Gnaedinger, and E. Doering, "Photolithography in anisotropically etched grooves," in Proc. IEEE 9th Annu. Int. Workshop Micro Electro Mech. Syst., 1996, pp. 38-43.

[34] G. Genolet, M. Despont, P. Vettiger, D. Anselmetti, and N. F. de Roij, "All-photoplastic, soft- cantilever cassette probe for scanning force microscopy," J. Vac. Sci. Technol. B, Microelectron. Process. Phenom., vol. 18, no. 2, p. 617, Mar. 2000.

[35] G. M. Kim, B. Kim, M. Liebau, J. Huskens, D. N. Reinhoudt, and J. Brugger, "Surface modification with self-assembled monolayers for nanoscale replication of photoplastic MEMS," J. Microelectromech. Syst., vol. 11, no. 3, pp. 175-181, Jun. 2002.

[36] M. Elwenspoek and H. Jansen, Silicon Micromachining. Cambridge, U.K.: Cambridge Univ. Press, 1998.

[37] M. Alavi, S. Büttgenbach, A. Schumacher, and H.-J. Wagner, "Fabrication of microchannels by laser machining and anisotropic etching of silicon," Sens. Actuators A, Phys., vol. 32, no. 1-3, pp. 299-302, 1992.

[38] R. E. Oosterbroek, J. W. Berenschot, H. V. Jansen, A. J. Nijdam, G. Pandraud, A. van den Berg, and M. C. Elwenspoek, "Etching methodologies in 111-oriented silicon wafers," J. Microelectromech. Syst., vol. 9, no. 3, pp. 390-398, 2000.

[39] M. J. de Boer, J. G. E. Gardeniers, H. V. Jansen, E. Smulders, M.-J. Gilde, G. Roelofs, J. N. Sasserath, and M. Elwenspoek, "Guidelines for etching silicon MEMS structures using fluorine high-density plasmas at cryogenic temperatures," J. Microelectromech. Syst., vol. 11, no. 4, pp. 385-401, 2002.

[40] S. Kuiper, M. de Boer, C. van Rijn, W. Nijdam, G. Krijnen, and M. Elwenspoek, "Wet and dry etching techniques for the release of submicrometer perforated membranes," J. Micromech. Microeng., vol. 10, no. 2, pp. 171-174, 2000

[41] J. W. Berenschot, N. R. Tas, T. S. J. Lammerink, M. Elwenspoek, and A. van den Berg, "Advanced sacrificial poly-Si technology for fluidic systems," J. Micromech. Microeng., vol. 12, no. 5, pp. 621-624, Sep. 2002.

[42] M. B. Stern, M. W. Geis, and J. E. Curtin, "Nanochannel fabrication for chemical sensors," J. Vac. Sci. Technol. B, Microelectron. Process. Phenom., vol. 15, no. 6, pp. 2887-2891, Nov. 1997.

[43] E. X. Vrouwe, R. Luttge, W. Olthuis, and A. van den Berg, "Microchip analysis of lithium in blood using moving boundary electrophoresis and zone electrophoresis," Electrophoresis, vol. 26, no. 15, pp. 3032-3042, Aug. 2005.

[44] E. X. Vrouwe, R. Luttge, and A. van den Berg, "Sampling for pointof care analysis of lithium in whole blood with chip based CE," in Proc. $\mu$ TAS 8th Int. Conf. Miniaturized Syst. Chem. Life Sci., T. Laurell, J. Nilsson, K. Jensen, D. J. Harrison, and J. P. Kutter, Eds., Malmö, Sweden, Sep. 26-30, 2004, pp. 503-505.

[45] A. Wolff, I. R. Perch-Nielsen, U. D. Larsen, P. Friis, G. Goranovic, C. R. Poulsen, J. P. Kutter, and P. Telleman, "Integrating advanced functionality in a microfabricated high-throughput fluorescent-activated cell sorter," Lab Chip Chem. Biol., vol. 3, no. 1, pp. 22-27, Jan. 2003.

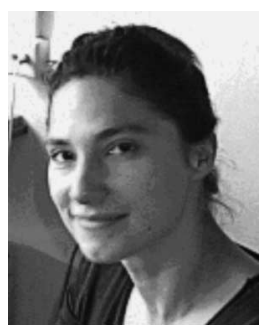

Regina Luttge received the B.Sc. degree in applied science from Fachhochschule Wiesbaden, Wiesbaden, Germany, in 1993.

She worked on LIGA developments at the Institute für Mikrotechnik Mainz (IMM), Germany, for fourand-a-half years. After her Ph.D. project concerning microtechnological enhancements of optical scanning devices at Imperial College London, U.K., she started working as a research member at the MESA ${ }^{+}$ Institute for Nanotechnology, University of Twente, Enschede, The Netherlands, in the Transducer Science and Technology group, in May 2001. At the same time, she was a research member of the strategic research orientation Micro (Bio) Chemical Systems, headed by Prof. A. van den Berg. In 2003, she joined the Lab-on-a-Chip group of Prof. van den Berg as a Postdoctoral Research Fellow. Her main research expertise is in micromachining and device integration, with applications in the field of miniaturized optical, fluidic, and medical analysis systems, as well as drug delivery. Recently, she has focused on new methodologies for top-down nanolithographic techniques as a Senior Scientist in the Systems and Materials for Information storage group, headed by L. Abelmann, while continuing to work part-time on the microneedle research with van den Berg's group. She was one of the organizers of the World Micromachine Summit in 2002. She has published 12 reviewed journal papers on microfabrication and Lab-on-a-Chipbased systems.

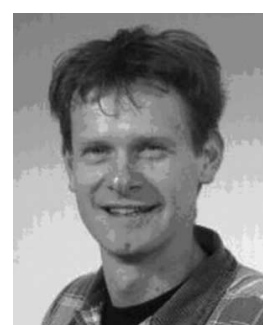

Erwin J. W. Berenschot received the B.Sc. degree in applied physics from the Technische Hogeschool, Enschede, The Netherlands, in 1990.

Since 1992, he has been a Micromachining Engineer with the Transducer Science and Technology group of the $\mathrm{MESA}^{+}$Institute for Nanotechnology, University of Twente, Enschede. His main research area is development and characterization of etching and deposition techniques for the fabrication of microsystems. He has published over 30 reviewed journal papers on micromachining and related topics, and five patent applications.

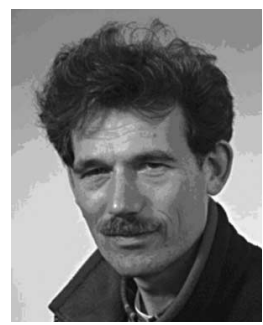

Meint J. de Boer was with the company Sentron in Roden, The Netherlands, as a Process Engineer in 1982, where he worked in the field of $\mathrm{pH}$-sensors and pressure sensors for medical applications. In 1988, he was with the Department of Applied Physics at the University of Groningen, The Netherlands, where he focused on nanoengineering for fundamental research on superconductivity. Since 1992, he has been with the Transducer Science and Technology Group at the $\mathrm{MESA}^{+}$Institute for Nanotechnology, University of Twente, Enschede, The Netherlands. His current research interests include silicon micromachining and related fabrication techniques, with a focus on deep reactive-ion etching techniques. $\mathrm{He}$ has published over 20 reviewed journal papers on micromachining and related topics, and four patent applications.

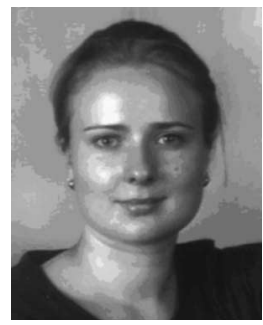

Dominique M. Altpeter was born in Saarbruecken, Germany, in 1979. She received the Diploma degree in engineering, with the special subject microsystem technology, in 2002 from the University of Applied Sciences Kaiserslautern, Zweibruecken, Germany, where she is currently working toward the Master's degree.

For one-and-a-half years, she worked on the development of a structured coating process on polyimide substrates using electroplating, which was carried out at the Fraunhofer Institute for Biomedical Engineering. Her diploma thesis "process development for polymer needles by using SU-8 technology and silicon molding techniques" was carried out at the $\mathrm{MESA}^{+}$Institute for Nanotechnology, University of Twente, Enschede, The Netherlands. Since 2002, she has been a Technical Staff Member at MESA ${ }^{+}$ Her current work focuses on layers and patterning of different (photo) resist materials. In January 2003, she was with the management of LSM. She has copublished one patent.

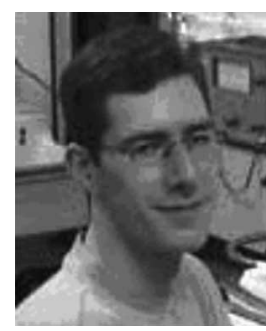

Elwin X. Vrouwe received the B.Sc. degree after a laboratory education (Hoger Laboratorium Onderwijs), with a specialization in analytical chemistry, from Leidse Hogeschool, Leiden, The Netherlands, in 1997, and the M.Sc. degree in chemistry from Leiden University, Leiden, in 2001. He received the Ph.D. degree from the MESA ${ }^{+}$Institute for Nanotechnology, University of Twente, Enschede, The Netherlands, in the Biosensors/Labon-a-Chip group in 2005.

During his education, he worked on projects in the field of atomic absorption spectrometry (Technical University of Delft), capillary electrophoresis and mass spectrometry interfaces (Leiden University), and molecularly imprinted polymers on quartz crystal microbalances (Nottingham Trent University, U.K.). His main expertise is in instrumental analysis, which is currently focused on chip-based systems. Currently, he holds a research position at Micronit Microfluidics B.V., The Netherlands. He has published five reviewed journal papers on analytical and Lab-on-a-Chip microanalytical techniques. 


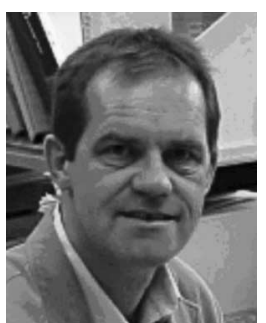

Albert van den Berg received the M.Sc. and Ph.D. degrees in applied physics from the University of Twente, Enschede, The Netherlands, in 1983 and 1988, respectively.

From 1988 to 1990, he was with the Swiss Center for Microelectronics and Microtechnology, Neuchâtel, Switzerland, as a Project Manager in the Chemical Sensors Department. From 1990 to 1993, he investigated miniaturized chemical sensor systems at the Institute of Microtechnology, University of Neuchâtel. In 1993, he started and since then has led the strategic research orientation "Micro (Bio) Chemical Systems" (MiCS) at the MESA ${ }^{+}$Institute for Nanotechnology at the University of Twente, where he was appointed Full Professor in 1998. He has been the Chair of "Biosensors/ Lab-on-a-Chip," which is part of the Department of Electrical Engineering, Mathematics and Informatics at the University of Twente, since August 2002. He has published more than 70 reviewed papers on $\mu$ TAS-related subjects. His current research interests are theory, technologies, new devices, and applications of micro- and nanofluidics for miniaturized (bio) chemical synthesis, analysis, and dosing systems.

Dr. van den Berg received the prestigious Simon Stevin Meester award from STW, the Dutch Technology Foundation, in 2002. He is a member of the Scientific Committee of the European Conference on Micro- and Nanotechnologies for Life Sciences (NanoTech), the Scientific Committee of the $\mu$ TAS conferences, the $\mu$ TAS Steering Committee, the Advisory Board of the 4th International Micromachine Symposium, the Steering Committee of the International Transducers Conference series, and is Chair of the Gordon Research Conference on Physics and Chemistry of Micro Fluidics in 2003, and Organizer of the Micromachine Summit in 2002.

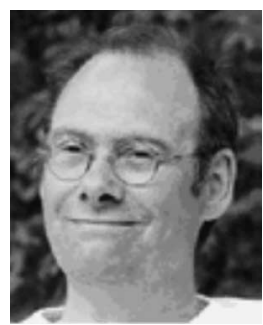

Miko Elwenspoek was born in Eutin, Germany, on December 9, 1948. He received the Master's degree in physics, focusing on Raleigh scattering from liquid glycerol using light coming from a Mössbauer source, and the Ph.D. degree from the Freie Universität Berlin, Berlin, Germany, in 1983.

From 1977 to 1979, he worked with Prof. Helfrich on lipid double layers. In 1979, he had been working toward the Ph.D. degree with Prof. Quitmann on the subject of relaxation measurements on liquid metals and alloys, in particular, alkali metal alloys. In 1983, he moved to Nijmegen, The Netherlands, to study crystal growth of organic crystals in the group of Prof. Bennema at the University of Nijmegen. In 1987, he moved to the University of Twente, Enschede, The Netherlands, to take charge of the micromechanics group of the Sensors and Actuators Laboratory, currently called the MESA ${ }^{+}$Institute for Nanotechnology. Since then, his research has focused on microelectromechanical systems, including design and modeling of micropumps, resonant sensors, and electrostatic microactuators for microrobots. Fabrication techniques such as the physical chemistry of wet chemical anisotropic etching, reactive-ion etching, wafer bonding, chemical-mechanical polishing, and the materials science of various thin films are his primary interests. Since 1996, he has been a Full Professor in the Transducer Science and Technology group, Faculty of Electrical Engineering, University of Twente. 